\title{
Protective Factors and Resilience in Older Adults
}

Katelyn Gullatt, Caroline Lee, \& Jessica McClain

Capstone Advisor: Susan Morris, PhD, OTR/L

Occupational Therapy Department, Dominican University of California

\section{INTRODUCTION}

- Older adults are the fastest growing demographic in the United States, many desiring to age at home $(1,2)$.

- Protective factors support resilience promote successful aging in place (3).

- The most effective protective factors supporting resilience in older adults are unknown.

\section{STATEMENT OF PURPOSE}

The purpose of this study was to investigate whether the three protective factors (physical health, social support, and self-efficacy) collectively predict resilience in Marin County older adults who desire to age in place.

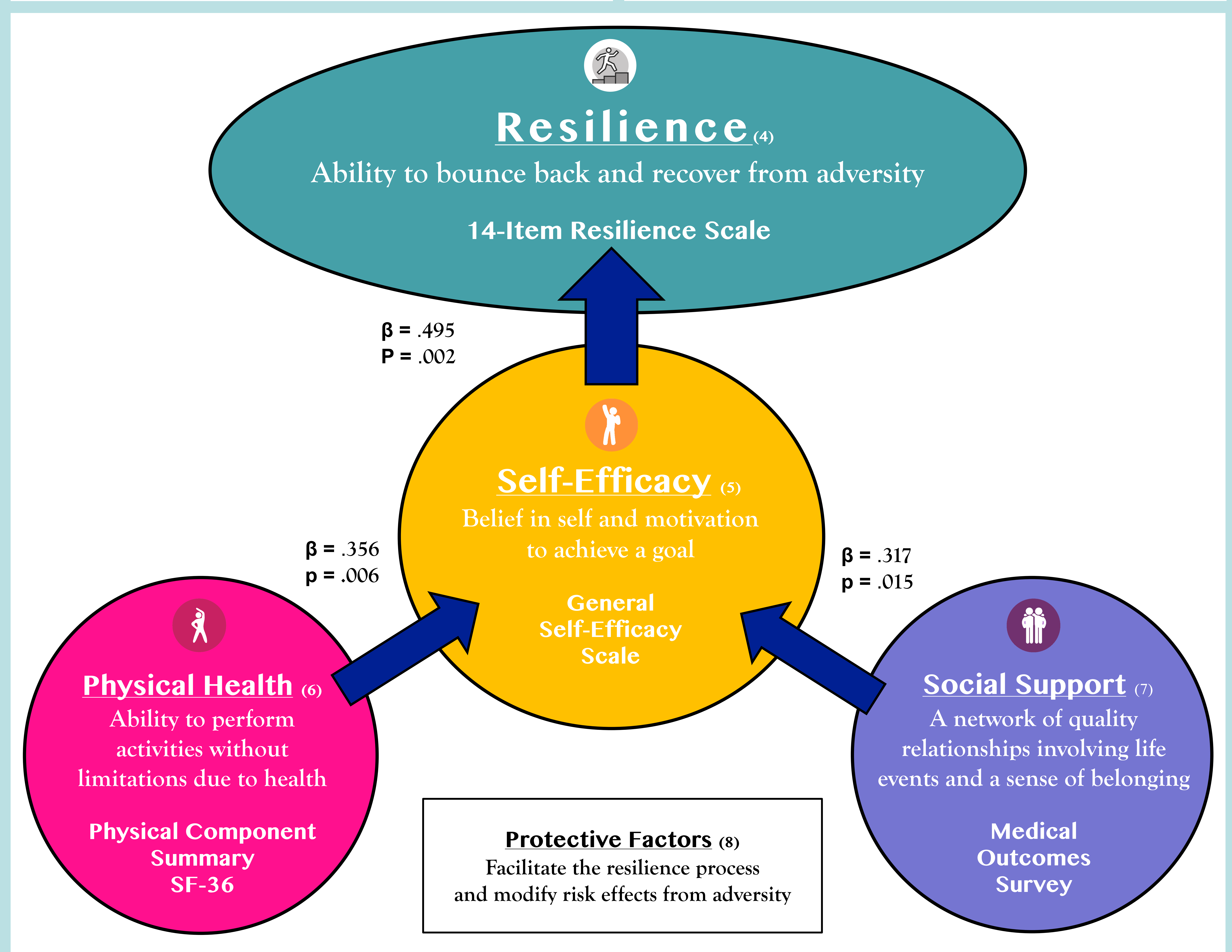

